\title{
Crescimento inicial de Colubrina glandulosa Perkins var. reitzii (M.C. Johnston) M.C. Johnston em campo e viveiro sob diferentes intensidades de luz
}

\author{
Ricardo Messias $^{1^{*}}$ \& Maria Terezinha Silveira Paulilo ${ }^{1}$
}

Enviado em outubro de 2012; aceito em novembro de 2012.

\section{Resumo}

Em vista do uso de Colubrina glandulosa Perkins var. reitzii (M.C. Johnston) M.C. Johnston, sobraji, na regeneração de florestas e em exploração comercial, este trabalho estudou aspectos do desenvolvimento de plântulas tanto em viveiro como no campo em ambientes das Florestas Ombrófilas Densas Submontana e de Terras Baixas. Para verificar o primeiro objetivo, plantas foram cultivadas em viveiro sob 100,50 e $20 \%$ da luz solar total e solo adubado ou solo retirado de Floresta de Terras Baixas. Para verificação do segundo objetivo, sementes da espécie foram semeadas em cinco parcelas em ambientes de Floresta Ombrófila Densa Submontana e Floresta Ombrófila Densa de Terras Baixas. As plantas em viveiro crescidas a pleno sol apresentaram menor biomassa total, de raiz e de caule, que plantas a $20 \%$ de luz solar plena. A taxa de crescimento relativo (TCR), número de folhas, diâmetro do coleto e área foliar, também foi menor a pleno sol. Comparação entre plantas sob uma mesma intensidade luminosa, em substratos de solo de floresta e solo adubado, mostra que o solo de floresta foi menos favorável ao acúmulo de biomassa, área foliar, número de folhas e altura de plantas. Em plantas a pleno sol a TCR foi bem menor em solo de floresta em relação ao solo adubado. A semeadura direta em ambiente de Floresta de Terras Baixas não apresentou emergência de nenhum indivíduo mostrando uma não adaptação da espécie a este ambiente em decorrência das freqüentes inundações. Em ambiente de Floresta Submontana a espécie apresentou maior desenvolvimento nas parcelas com maior irradiância. As plantas que cresceram nas parcelas recebendo menor irradiância mostraram menor altura e menor diâmetro à altura do colo que plantas crescendo em parcelas com irradiância mais alta.

Palavras-chave: Crescimento inicial, semeadura direta, luz e substrato.

\footnotetext{
DOI: http://dx.doi.org/10.5007/2178-4574.2012n41p73

${ }^{1}$ Programa de Pós-Graduação em Biologia Vegetal, Departamento de Botânica, CCB, Universidade Federal de Santa Catarina, Campus Universitário, Trindade, CEP:88040-900 - Florianópolis

* e-mail para correspondência: ramessias@hotmail.com
}

\section{(cc) Bry-Ne artigo é de Acesso Livre, disponibilizado sob os termos da}

Creative Commons Attribution 3.0 Unported License (http://creativecommons.org/licenses/by/3.0/) que permite uso não-comercial, distribuição e reprodução em qualquer meio, desde que este trabalho original seja devidamente citado. 


\begin{abstract}
[Initial growth of Colubrina glandulosa Perkins var. reitzii (M.C. Johnston) M.C. Johnston in field and greenhouse under different light intensity]. In view of the uses of Colubrina glandulosa Perkins var. reitizi (M.C. Johnson) M.C. Johnson, sobraji, in forest regeneration and commercial exploration, this work studied aspects of the development of seedlings in field (Lowland Dense Ombrophilous and Submontane Dense Ombrophilous Forest) and in greenhouse. This was done by direct sowing, in greenhouse, under three different light intensities and using two substrata types. Plants grown under direct sunlight showed lower total biomass, root biomass and stem biomass when compared to plants grown under $20 \%$ of full sunlight. In forest soil, plants grown under full sunlight showed lower stem, root and leaf biomass when compared to plants grown under $20 \%$ and $50 \%$ of sunlight. The RGR (relative growth rate), leaf number, diameter of the root collar and leaf area were also lower under full sunlight. The comparison between plants grown under the same light intensity, but on different substrata, indicates that forest soil was less favorable for biomass accumulation and leaf and stem growth. Plants grown under full sunlight showed a much lower RGR on forest soil. There was no plant emergence after direct seed sowing on Low Land Forest, possibly because of frequent floods. In Submontane Forest, the species show higher development under higher sunlight levels. Plants grown under lower light intensity showed lower height and root collar diameter than plants grown under higher light intensity.
\end{abstract}

Key words: Initial growth, direct sowing, light, substrata

\title{
Introdução
}

A Floresta Tropical Atlântica em Santa Catarina está restrita a fragmentos florestais secundários e poucos relictos de formações primárias, sendo muitos deles bastante deturpados por cortes seletivos das madeiras mais nobres (IBGE 1990). Este fracionamento dificulta a regeneração natural das florestas, pois compromete a produção e a disseminação de sementes (Reis et al. 1992). A introdução de espécies constitui uma alternativa capaz de acelerar o processo sucessório e uma das formas de introdução das espécies de interesse é através da semeadura direta (Mattei \& Rosenthal 2002).

Cada espécie tem exigências próprias para seu desenvolvimento e luz, água, temperatura e condições edáficas são alguns dos fatores do meio que influem no desenvolvimento da vegetação (Treshow 1970).

Colubrina glandulosa Perkins var. reitizi (M.C. Johnson) M.C. Johnson, vulgarmente conhecida por sobraji, é uma das poucas espécies nativas com possibilidades de reflorestamento homogêneo, ou associado a outras espécies pioneiras como o jacatirão e a licurana, que desempenham ecologicamente o mesmo papel nas matas secundárias (Reitz et al. 1978) Em alguns municípios do Vale do 
Itajaí, há cultivos bem sucedidos do sobraji e muitos colonos costumam cultivá-la há mais de meio século; sendo as plantações existentes nesta região feitas em agrupamentos puros, ou dentro de capoeiras.

Diante da carência de informações relativas ao desenvolvimento de espécies nativas, da importância da intensidade da luz neste desenvolvimento e da necessidade de elaboração de modelos economicamente viáveis de recuperação, o presente trabalho tem o objetivo de conhecer ao sombreamento e tipos de solo de mudas de Colubrina glandulosa e verificar a viabilidade de implantação desta espécie, via semeadura direta, em dois ambientes de Mata Atlântica, os ambientes das Florestas Ombrófila Densa Submontana e de Terras Baixas.

\section{Material e Métodos}

Sementes de Colubrina glandulosa var. reitzii (M.C. Johnston) M.C. Johnston foram colhidas de diversas matrizes localizadas no Bairro Canto da Lagoa, em Florianópolis, SC em uma área preservada de Mata Atlântica. O experimento foi conduzido no período de novembro de 2006 a junho de 2007, em viveiro do Departamento de Botânica, da Universidade Federal de Santa Catarina (UFSC), Florianópolis, e em áreas de ocorrência de Florestas Ombrófila Densa Submontana e de Terras Baixas localizadas no sul da ilha de Florianópolis, $48^{\circ} 31^{\prime} 14.83$ "W e $27^{\circ}$ 46'06.19" S.

Em viveiro, sementes foram colocadas para germinar em sacos plásticos de $10 x 25 \mathrm{~cm}$ (três sementes por recipiente) contendo substrato constituído de terriço de mata adicionado de compostagem húmica na proporção de 1:1 (solo adubado) ou solo de Floresta de Terras Baixas (solo de floresta). As plântulas foram colocadas a 100\%, $50 \%$ e $20 \%$ da luz solar direta. O corte de luz foi dado colocando-se as plantas sob caixas de $1 \mathrm{~m}^{3}$, confeccionadas com tela sombrite de diferentes malhas. Foram utilizadas 9 plântulas por tratamento com 3 repetições, constituindo-se de 27 plântulas por tratamento e 81 plântulas no total do experimento. Dez dias após a emergência foi deixada apenas uma plântula por saco plástico, a de maior altura. As sementes, antes de serem semeadas, foram colocadas por duas horas em ácido sulfúrico concentrado para a quebra de dormência tegumentar (Fowler \& Bianchetti 2000). Para as medidas de luz foi utilizado quantômetro LICOR 250, com sensor para radiação fotossintéticamente ativa. As irradiâncias a pleno sol medidas em dia claro às 12:00 horas, nos meses de janeiro e julho de 2007 , foram de $1732,7 \mu \mathrm{mol} \mathrm{m}^{-2} \mathrm{~s}^{-1} \mathrm{e} 641,9$ $\mu \mathrm{mol} \mathrm{m} \mathrm{m}^{-2} \mathrm{~s}^{-1}$ respectivamente. $\mathrm{O}$ experimento foi montado em distribuição completamente casualizada, contando cada tratamento com três unidades experimentais.

Em campo, em ambientes de Florestas Ombrófilas Densas Submontana e de Terras Baixas, foram marcadas cinco parcelas de $36 \mathrm{~m}^{2}$ por ambiente. Cada parcela foi composta de nove covas de $5 \mathrm{~cm}$ de profundidade, espaçadas entre si por uma distância de 1,5m, totalizando 45 indivíduos no tratamento. Em cada cova foram 
semeadas três sementes e após a emergência de plântulas, foi deixado apenas um indivíduo por cova, aquele de maior tamanho. $\mathrm{O}$ experimento foi montado em distribuição completamente casualizada, havendo por tratamento cinco unidades experimentais.

A análise da composição do solo de floresta e do solo adubado utilizado em viveiro é apresentada na Tabela1 e as medidas de luz nas parcelas, na Tabela 2.

O diâmetro à altura do colo foi determinado com a ajuda de um paquímetro de aço carbono, marca WORKER de precisão de $0,02 \mathrm{~mm}$. Altura de plantas mensurada com fita métrica metálica FEELING de $3 \mathrm{~m}$ de comprimento, medindo-se o comprimento da planta desde o coleto. Para a obtenção da massa seca, as plantas foram separadas em raiz, caule e folhas, e colocadas em estufa a $80^{\circ} \mathrm{C}$ por 48 horas. A área foliar foi obtida com o uso de um planímetro PLACON KP - 80N. A taxa de

Tabela 1. Análise de solos das Florestas Submontana e de Terras Baixas e do solo adubado utilizado em viveiro.

\begin{tabular}{ccccc}
\hline Características & $\begin{array}{c}\text { Solo de Floresta } \\
\text { Submontana }\end{array}$ & Solo adubado & $\begin{array}{c}\text { Solo de Floresta } \\
\text { de Terras Baixas }\end{array}$ & Unidades \\
\hline Textura & 20 & 19 & 25 & \% Argila \\
\hline pH & 5,20 & 6,40 & 4,00 & \\
\hline Indice SMP & 5,60 & 7,00 & 4,20 & \\
\hline Fósforo & 5,70 & 50,00 & 11,00 & $\mathrm{ppm}$ \\
\hline Potássio & 149,00 & 216,00 & 109,00 & $\mathrm{ppm}$ \\
\hline Matéria Orgânica & 9,10 & 2,00 & $>10,00$ & $\%(\mathrm{~m} / \mathrm{v})$ \\
\hline Alumínio & 0,00 & 0,00 & 2,70 & $\mathrm{cmolc} / 1$ \\
\hline Cálcio & 10,00 & 3,50 & 6,90 & $\mathrm{cmolc} / 1$ \\
\hline Magnésio & 5,40 & 1,70 & 1,80 & $\mathrm{cmolc} / 1$ \\
\hline Sódio & 61,00 & 30,00 & 93,00 & $\mathrm{ppm}$ \\
\hline $\mathrm{H}^{+}$Al & 6,90 & 1,38 & 34,45 & $\mathrm{cmolc} / 1$ \\
\hline Soma Bases-S & 16,06 & 5,89 & 9,40 & $\mathrm{cmolc} / 1$ \\
\hline CTC & 22,96 & 7,27 & 43,85 & $\mathrm{cmolc} / 1$ \\
\hline Saturação Bases & 69,95 & 81,02 & 21,44 & $\%$ \\
\hline
\end{tabular}

Interpretação conforme Sociedade Brasileira Ciências do Solo - Núcleo Regional Sul / EMBRAPA-CNPT, 2004. Companhia Integrada de Desenvolvimento Agrícola de Santa Catarina-CIDASC. 
crescimento relativo TCR foi calculada pela equação $T C R=\left(\ln \mathrm{M}_{2}-\ln \mathrm{M}_{1}\right) /\left(\mathrm{T}_{2}-\mathrm{T}_{1}\right)$, a razão de área foliar (RAF), pela equação $R A F=\left[\left(A_{1} / M_{1}\right)+\left(A_{2} / M_{2}\right)\right] / 2$ (Hunt 1982), onde $\mathrm{T}_{1}$ e $\mathrm{T}_{2}$ representam a época da primeira e segunda coletas, aos 30 e 210 dias após a emergência; $M_{1}, M_{2}, A_{1}$ e $A_{2}$ representam a massa seca total e área foliar das plantas na primeira e segunda coletas.

Tabela 2. Irradiância ( $\mu$ mol fótons $\mathrm{m}^{-2} \mathrm{~s}^{-1}$ ) e porcentagem de luz (\%) em relação à luz solar plena ao longo do dia em parcelas de semeadura direta em área de Floresta Ombrófila Densa Submontana

\begin{tabular}{|c|c|c|c|c|c|c|}
\hline $\begin{array}{l}\text { Horas do } \\
\text { dia }\end{array}$ & 8:00 & $12: 00$ & $16: 00$ & 8:00 & $12: 00$ & $16: 00$ \\
\hline & \multicolumn{3}{|c|}{$\left(\mu \mathrm{mol}\right.$ fótons $\mathrm{m}^{-2} \mathrm{~s}^{-1}$ ) } & \multicolumn{3}{|c|}{$\begin{array}{c}\% \text { de irradiância em relação ao } \\
\text { sol pleno }\end{array}$} \\
\hline Parcela 1 & 9,68 & 14,61 & 9,45 & 3,42 & 2,27 & 2,93 \\
\hline Parcela 2 & 17,39 & 66,28 & 24,79 & 6,14 & 10,32 & 7,69 \\
\hline Parcela 3 & 16,35 & 37,68 & 26,45 & 5,77 & 5,87 & 8,21 \\
\hline Parcela 4 & 5,95 & 14,90 & 7,25 & 2,10 & 2,32 & 2,25 \\
\hline Parcela 5 & 2,28 & 9,11 & 5,04 & 0,81 & 1,41 & 1,56 \\
\hline Pleno sol & 283,00 & 64,90 & 322,15 & 100 & 100 & 100 \\
\hline
\end{tabular}

As médias entre tratamentos foram comparadas por análise de variância multifatorial, seguida de teste de Tukey e correlação de Spearman através do programa computacional BIOESTAT (2003).

\section{Resultados e Discussão}

Em plantas crescidas em solo adubado a biomassa total, de raiz e de caule, o diâmetro à altura do colo, a razão raiz/parte aérea e o número de folhas foram maiores que em plantas crescidas em solo de floresta, em quaisquer das irradiâncias aplicadas. Já a área foliar, a TCR e a RAF foram influenciadas pelo tipo de substrato dependendo da irradiância aplicada. Desta forma, a TCR foi afetada pelo substrato em plantas a pleno sol, mas não em plantas sombreadas. A RAF e a razão massa seca do caule pela altura do caule (MSC/AC) foram afetadas pelo substrato em plantas a pleno sol e a $20 \%$ de luz, enquanto a área foliar a $50 \%$ e $20 \%$ da luz solar. A altura do caule foi maior em solo adubado que em solo de floresta à exceção da irradiância a pleno sol. Nesta irradiância, tanto solo adubado como solo de floresta proporcionaram igual altura às plantas (Tabela 3 ). 
Tabela 3. Massa seca (MS) de raiz, caule, folhas, total, altura e razão massa seca de caule por altura de caule, Taxa média de crescimento relativo (TCR), razão média de área foliar (RAF), área foliar, número de folhas, diâmetro a altura do colo (DAC) e razão raiz/parte aérea (R/PA).de plantas de Colubrina glandulosa crescidas em viveiro por 210 dias, em diferentes substratos e irradiâncias

\begin{tabular}{|c|c|c|c|c|c|c|}
\hline$\%$ de luz & $\begin{array}{c}\text { MS Raiz } \\
\text { (g) }\end{array}$ & $\begin{array}{c}\text { MS Caule } \\
\text { (g) }\end{array}$ & $\begin{array}{c}\text { MS Folhas } \\
\text { (g) }\end{array}$ & $\begin{array}{c}\text { MS Total } \\
\text { (g) }\end{array}$ & $\begin{array}{c}\text { Altura } \\
\text { caule } \\
(\mathrm{cm})\end{array}$ & $\begin{array}{c}\text { MSC/AC } \\
(\mathrm{g} / \mathrm{cm})\end{array}$ \\
\hline $100 \% \mathrm{SA}$ & $2,71 b$ & $1,15 b$ & $3,65 \mathrm{ab}$ & $7,33 \mathrm{~b}$ & $22,08 \mathrm{bc}$ & $0,05 \mathrm{a}$ \\
\hline $50 \% \mathrm{SA}$ & $3,27 b$ & $1,66 \mathrm{ab}$ & $4,58 \mathrm{a}$ & $9,50 \mathrm{ab}$ & $31,00 \mathrm{~b}$ & $0,05 \mathrm{a}$ \\
\hline $20 \% \mathrm{SA}$ & $4,22 \mathrm{a}$ & $2,16 a$ & $4,65 \mathrm{a}$ & $11,00 \mathrm{a}$ & $48,73 a$ & $0,04 a$ \\
\hline $100 \% \mathrm{SF}$ & $0,20 \mathrm{~d}$ & $0,40 \mathrm{c}$ & $0,80 \mathrm{c}$ & $1,40 \mathrm{c}$ & $16,60 \mathrm{c}$ & $0,02 b$ \\
\hline $50 \% \mathrm{SF}$ & $0,90 \mathrm{c}$ & $0,93 \mathrm{c}$ & $2,65 b$ & $3,65 \mathrm{~d}$ & $18,57 \mathrm{c}$ & $0,05 \mathrm{a}$ \\
\hline $20 \%$ SF & $1,06 \mathrm{c}$ & $1,00 \mathrm{~d}$ & $2,95 \mathrm{~b}$ & $4,33 \mathrm{~d}$ & $30,86 b$ & $0,03 \mathrm{~b}$ \\
\hline$\%$ de luz & $\begin{array}{c}\text { TCR } \\
\left(\mathrm{mg} \mathrm{mg}^{-1}\right. \\
\left.\operatorname{dia}^{1}\right)\end{array}$ & $\begin{array}{c}\text { RAF } \\
\left(\mathrm{cm}^{2} \mathrm{mg}^{-1}\right)\end{array}$ & $\begin{array}{c}\text { Área foliar } \\
\left(\mathrm{cm}^{2}\right)\end{array}$ & $\mathrm{N}^{\circ}$ de folhas & $\begin{array}{l}\text { DAC } \\
(\mathrm{cm})\end{array}$ & R/PA \\
\hline $100 \% \mathrm{SA}$ & $0,026 a$ & $116,36 b$ & $497,43 \mathrm{~cd}$ & $9,50 \mathrm{ac}$ & $0,53 b$ & $0,56 b$ \\
\hline $50 \% \mathrm{SA}$ & $0,027 \mathrm{a}$ & $122,76 b$ & $733,15 b$ & $10,00 \mathrm{ac}$ & $0,65 \mathrm{a}$ & $0,52 b$ \\
\hline $20 \% \mathrm{SA}$ & $0,027 \mathrm{a}$ & $117,27 b$ & $1093,50 a$ & $10,16 \mathrm{a}$ & $0,66 \mathrm{a}$ & $0,62 \mathrm{a}$ \\
\hline $100 \% \mathrm{SF}$ & $0,016 b$ & $161,47 a$ & $141,00 \mathrm{~d}$ & $4,11 b$ & $0,27 \mathrm{~d}$ & $0,41 \mathrm{c}$ \\
\hline $50 \%$ SF & $0,023 \mathrm{a}$ & $125,43 \mathrm{ab}$ & $384,43 \mathrm{~cd}$ & $6,77 \mathrm{c}$ & $0,43 c$ & $0,25 \mathrm{~d}$ \\
\hline $20 \%$ SF & $0,024 a$ & $146,87 \mathrm{a}$ & $625,13 b c$ & $7,66 \mathrm{c}$ & $0,42 \mathrm{c}$ & $0,27 d$ \\
\hline
\end{tabular}

Valores seguidos da mesma letra na coluna não diferem estatisticamente entre si ao nível de 5\% de probabilidade pelo teste de Tukey. Solo adubado (SA) e solo de floresta de terras baixas (SF).

Values following by same letters in the column don't differ at the level of $5 \%$ of probability for the test of Tukey. Fertilized soil (SA) and soil of lowland forest (SF).

Pelos resultados do crescimento das plantas em viveiro observa-se que, para crescimento em termos de biomassa, o solo de floresta proporcionou um crescimento inferior que o solo adubado. Este crescimento foi tão inferior que as alterações no nível de irradiância não conseguiram suplantar o efeito do substrato de crescimento. Observando a composição do solo oriundo de ambiente de Floresta de Terras Baixas e 
a do solo adubado (Tabela 1) vê-se que o solo adubado possui níveis mais altos de fósforo e potássio, bem como maior saturação de bases e CTC (carga de troca catiônica) e acidez potencial $\left(\mathrm{H}^{+} \mathrm{Al}\right)$ bem mais baixa. Estes fatores tornam o solo utilizado em viveiro mais fértil que o solo de floresta. Além disto, o alumínio, presente no solo de floresta pode resultar em toxidez, inibindo o crescimento das plantas e refletindo principalmente num menor desenvolvimento do sistema radicular (Delhaize \& Ryan 1995). Em solos ácidos, como os de floresta de Terras baixas, fatores outros além do alumínio e do $\mathrm{pH}$ podem estar restringindo o adequado desenvolvimento das plantas, já que o pH, indiretamente, influencia o desenvolvimento por interferir na disponibilidade de nutrientes no solo (Rending \& Taylor 1989). Em estudo de Neto et al. (1999), sobre o efeito da acidez do solo no comportamento de mudas das espécies florestais Senna multijuga (Rich.), Anadenanthera falcata (Benth.) Speg. e Cedrela fissilis Vell. verificou-se redução na matéria seca produzida tanto nas raízes quanto na parte aérea das espécies florestais, refletindo também na redução da altura e do diâmetro do caule de todas as espécies. Houve também uma tendência de menor absorção de $\mathrm{Ca}, \mathrm{Mg}, \mathrm{K}$ e $\mathrm{P}$, além da eficiência de utilização destes nutrientes pelas plantas ter sido também inibida, resultando em redução acentuada na produção relativa de matéria seca total.

As plantas crescidas em viveiro apresentaram crescimento em altura favorecido pela irradiância mais baixa. Outras espécies nativas de arbóreas consideradas heliófitas apresentaram resposta de estiolamento quando sombreadas, como Cecropia glazioui Sneth.(Duz et a., 2004) e Gallesia integrifólia (Spreng) Harms (Demuner et al. 2004).

O crescimento de C. glandulosa em biomassa foi menos favorecido a pleno sol, como também relatado por Caus e Paulilo (2000). Em solo de floresta as plantas a pleno sol apresentaram TCR muito mais baixa que a das plantas sombreadas, podendo a fotossíntese ter sido fotoinibida pelo excesso de radiação (Demmig-Adams \& Adams 1992) e agravado pela deficiência nutricional (Yanping et al. 2003).

As plantas no campo cresceram em diferentes parcelas, as quais receberam durante o dia diferentes irradiâncias (Tabela 4). Os dados para altura e diâmetro à altura do colo mostram que nas duas irradiâncias mais altas estes são menores que nas duas irradiâncias mais baixas. O número de folhas só foi significativamente diferente entre 5 e $26 \mu \mathrm{mol} \mathrm{m}^{-2} \mathrm{~s}^{-1}$, sendo menor na irradiância menor.

Um dos critérios para a expedição de mudas a campo é o diâmetro do colo, já que existe uma alta correlação entre este e a sobrevivência de mudas depois do plantio (Carneiro 1983). Este parâmetro sozinho ou em combinação com outros atributos das plântulas pode ser usado para relatar a qualidade dos estoques da planta, necessários ao sucesso campo (Bayley \& Kietzka 1996). C. glandulosa apresentou maior crescimento em DAC em condições de maiores valores de sombreamento, resultados também verificados em Goupia glabra Aubl. (Daniel et al. 1994). Plantas de C. glandulosa crescidas em viveiro apresentaram alta correlação entre diâmetro do colo e massa seca de raiz e massa seca total. 
Tabela 4. Altura, diâmetro a altura do colo (DAC), número de folhas, emergência e sobrevivência de plantas de Colubrina glandulosa implantadas por semeadura direta em área de Floresta Atlântica Submontana e crescidas durante 210 dias.

\begin{tabular}{ccccccc}
\hline Parcelas & $\begin{array}{c}\text { Irradiância } \\
\left(\mu \mathrm{mol} \mathrm{m}^{-2} \mathrm{~s}^{-1}\right)\end{array}$ & $\begin{array}{c}\text { Altura } \\
(\mathrm{cm})\end{array}$ & $\begin{array}{c}\text { Número } \\
\text { de folhas }\end{array}$ & $\begin{array}{c}\text { Diâmetro } \\
\text { a altura } \\
\text { do colo }\end{array}$ & $\begin{array}{c}\text { Emergência } \\
(\%)\end{array}$ & $\begin{array}{c}\text { Sobrevivência } \\
(\%)\end{array}$ \\
\hline 2 & 36 & $20,52 \mathrm{a}$ & $8,40 \mathrm{ab}$ & $0,26 \mathrm{a}$ & $11,11 \mathrm{~b}$ & $100 \mathrm{a}$ \\
3 & 26 & $22,53 \mathrm{a}$ & $9,40 \mathrm{ab}$ & $0,30 \mathrm{a}$ & $25,92 \mathrm{a}$ & $88 \mathrm{a}$ \\
1 & 11 & $17,23 \mathrm{ab}$ & $7,60 \mathrm{ab}$ & $0,22 \mathrm{a}$ & $29,62 \mathrm{a}$ & $100 \mathrm{a}$ \\
4 & 9 & $11,70 \mathrm{bc}$ & $6,40 \mathrm{ab}$ & $0,100 \mathrm{~b}$ & $18,51 \mathrm{c}$ & $80 \mathrm{a}$ \\
5 & 5 & $9,47 \mathrm{c}$ & $5,80 \mathrm{ab}$ & $0,100 \mathrm{~b}$ & $18,51 \mathrm{c}$ & $60 \mathrm{~b}$ \\
\hline
\end{tabular}

Sementes de $C$. glandulosa semeadas em Floresta de Terras Baixas não apresentaram emergência de plântulas durante todo o período de acompanhamento do experimento, possivelmente pelas longas e recorrentes inundações por água de precipitação pluviométrica no local do experimento. A mortalidade de propágulos, durante longos períodos de alagamento, tem um forte efeito nas taxas de estabelecimento, com considerável declínio no estabelecimento de plântulas após inundações (Bissels et al. 2006).

Na Floresta Submontana, a emergência de plantas iniciou-se quatro dias após a semeadura e estendeu-se até o $23^{\circ}$ dia, e, aparentemente o curto período de poucas chuvas ocorrido após o plantio parece ter afetado a emergência de plântulas, a qual apresentou valores de $11 \%$ a $29 \%$ entre as parcelas.

Apesar das baixas taxas de emergência, a espécie apresentou alta taxa de sobrevivência das plantas em campo e um bom crescimento, principalmente nas áreas com maior irradiância, confirmando o descrito para a espécie, como sendo de vegetação secundária, preferindo matas mais abertas, principalmente capoeirões, não participando do estrato dominante nas associações onde ocorre, sendo também, rara na floresta primaria sombria (Lorenzi 1998).

Estudos mostram uma forte e significante correlação entre diâmetro do colo e muitas características da raiz (inclusive volume e massa de raízes), que influenciam o desempenho das plântulas a campo (Jacobs et al. 2005). Este parâmetro sozinho ou em combinação com outros atributos das plântulas pode ser usado para relatar a qualidade dos estoques da planta, necessários ao sucesso a campo (Bayley \& Kietzka, 1996). 


\section{Referências}

Bayley, A.D.; Kietzka, J.W. 1996. Stock quality and field performance of Pinus patula seedlings produced under two nursery growing regimes during seven different nursery production periods. New Forest 13: 337-352.

Bissels, S.; Donath, T.W; Holzel, N.; Otte, A. 2006. Effects of different mowing regimes on seedlings recruitment in a alluvial grasslands. Basic and Applied Ecology 7: 433-442.

BIOESTAT. 2003. Aplicações estatísticas nas áreas de ciências sociológicas e médicas. Manaus: Sociedade Civil Mamirauá, Brasília: MCT/CNPq.

Carneiro, J.G.A. 1983. Influência dos fatores ambientais e das técnicas de produção sobre o desenvolvimento de mudas florestais e a importância dos parâmetros que definem sua qualidade. Anais do V Simpósio Sobre Florestas Plantadas nos Neotrópicos Como Fonte de Energia. Viçosa, MG. Universidade Federal de Viçosa, p.10-24.

Caus, C., Paulilo, M.T.S. 2000. Influência da quantidade de luz no crescimento inicial de duas espécies arbóreas da Mata Atlântica. Insula 29: 107-115.

Daniel, O.; Ohashi, S.T.; Santos, R.A. 1994. Produção de mudas de Goupia glabra (cupiúba) efeito dos níveis de sombreamento e tamanhos de embalagens. Revista Árvore 18: 1-13.

Delhaize, E.; Ryan, P.R. 1995. Aluminum toxity and aluminum tolerance in plants. Plant Physiology 107: 315-321.

Demmig-Adams, B.; Adams, W.W. III. 1992. Photoprotection and other responses of plants to high light stress. Annual Review Plant Physiology 43: 599-626.

Demuner, V.G.; Hebling, S.A.; D’Agustinho, D.M. 2004. Efeito do sombreamento no crescimento inicial de Gallesia integrifólia (SPRENG) Harms. Boletim Museu Biologia Mello Leitão 17: 45-55.

Duz, S.R.; Siminski, A.; Santo, S.M.; Paulilo, M.T.S. 2004. Crescimento inicial de três espécies arbóreas da Floresta Atlântica em resposta variação na quantidade de luz. Revista Brasileira de Botânica 27: 587-596.

Fowler, J.P.; Bianchetti, A. 2000 Dormência em sementes florestais. Colombo: Embrapa Florestas.

Hunt, R. 1982. Planta growth curves: the functional approach to plant growth analysis. Edward Arnold Publishes: London.

IBGE - Instituto Brasileiro de Geografia e Estatística. 1990. Geografia do Brasil: Região Sul. Rio de Janeiro: IBGE. v. 2.

Jacobs, D.F.; Salifu, K.S.; Seirfert, J.R. 2005. Relative contribution of initial root and shoot morphology in predecting field performance of hardwood seedlings. New Forests 302-303: 235-251.

Lorenzi, H. 1998. Árvores Brasileiras, manual de identificação e cultivo de arbóreas nativas do Brasil. Nova Odessa: Ed.Plantarum.

Mattei, V.L.; Rosenthal, M.D. 2002. Semeadura direta de Canafistula (Pelthophorum 
dubium (Spreng.). Taub. no enriquecimento de capoeiras. Revista Árvore.26: 649-654.

Neto, A.E.F.; Resende, A.V.;Do Vale, F.R.; Faquim, V.;Fernandes, L.A.1999. Acidez do solo, crescimento e nutrição mineral de algumas espécies arbóreas na fase de muda. Revista Cerne 5: 34-39.

Reis, A; Fantini, A.C; Reis, M.S.; Guerra, M.P.; Doebeli, G. 1992. Aspectos sobre a conservação da biodiversidade e o manejo da Floresta Tropical Atlântica. Revista do Instituto Florestal 4:169-174.

Reitz, R., Klein, M, Reis, A. 1978. Projeto Madeira de Santa Catarina. Itajaí: Herbário Barbosa Rodrigues.

Rending, V.V.; TayloR, H.M. 1989. Principles of Soil-Plant Interrelationships. New York: Mcgraw-Hill.

Treshow. M. 1970. Environment and Plant Response. New York: McGraw-Hill.

Yanping, G.; Ping Zhao C.; Liang Cheng Z.; Shang Long Z. 2003. Aggravation of photoinhibition of photosynthesis by phosphorus deficiency stress and the function of xanthophyll cycle in citrus leaves. Plant Nutrition and Fertilizer Science 9: 359-363. 